\title{
GAMBARAN PENYEBAB TERJADINYA PEMBENGKAKAN PAYUDARA PADA IBU MENYUSUI DI POLINDES DESA MEDDELEN KECAMATAN LENTENG
}

Emdat Suprayitno, Program Studi Profesi Ners, Universitas Wiraraja

e-mail: emdats@yahoo.com

Iva Gamar Dian Pratiwi, Program Studi Kebidanan, Universitas Wiraraja

e-mail: kura_15587@yahoo.com

Zakiyah Yasin, Program Studi Profesi Ners, Universitas Wiraraja

e-mail: kebidanan.fik@gmail.com

\section{ABSTRAK}

Breast swelling occurs because breast milk is not sucked by the baby adequately, so the rest of the milk is collected in the duct system that resulted in swelling and Asi Dam. Static blood vessels and lymphs will result in increased intraductal pressure affecting the various segments of the breast, resulting in increased breast pressure. It can also occur due to a blockage in the milk ducts.

This study aims to determine the description of the causes of breast engorgement in Polindes Tunas Bunda Meddelan Village District Lenteng Sumenep Year 2015 The method used is descriptive research method, that is to know the description of causes of breast engorgement in Meddelan village Lenteng District Sumenep Regency 2015. Population in this research is as many as 25 breastfeeding mothers and the sample is total sampling. And the method of collecting data by using questionnaire. The data were analyzed with the frequency distribution in percentage (\%).

The results of the study on June 12, 2015 showed that of 25 breastfeeding mothers nearly half of the respondents had a severe stress level of 8 (32\%), almost half of respondents applied less than 12 (48\%) breastfeeding techniques, almost all respondents did breast care the less as many as 19 (76\%), almost half of respondents had mild breast swelling that is as much as 10 (40\%).

From the results of the study researchers suggest for the community, especially breastfeeding mothers in order to keep personal hygiene or breast care to prevent the occurrence of blockage and eventually experience breast engorgement.

Keywords: breastfeeding, care, breast, swelling.

\section{PENDAHULUAN}

Masalah pembengkakan payudara pada ibu menyusui sering kita temui di masyarakat. lbu nifas menganggap bahwa sakit yang diraksakan pada daerah payudara di anggap sakit biasa dan tidak perlu dikhawatirkan. Dari hasil wawancara di Polindes Tunas Bunda Desa Meddelan Kecamatan Lenteng kebanyakan ibu menyusui di Desa Meddelan mengalami pembengkakan payudara karena sebelum dan sesudah menyusui kurang menjaga kebersihan payudara.

Berdasarkan studi pendahuluan yang dilakukan oleh penulis di Polindes Tunas Bunda Desa Menddelan Kecamatan Lenteng di temukan ibu menyusui sejumlah 25 (100\%) orang. Jumlah tersebut terdiri dari ibu menyusui normal sebanyak $15(60 \%)$ orang dan ibu menyusui yang mengalami bengkak pada payudara sebanyak 10 (40\%) orang.

Hasil survei Demografi dan Kesehatan Indonesia (SDKI) pada tahun 2008-2009 didapatkan data $55 \%$ ibu menyusui terjadi lecet pada putting susu dan mastitis yang penyebabnya kurangnya pengetahuan ibu yang kurang tentang perawatan payudara selama kehamilan, masa menyusui serta (Subujaktosaja, 2011).

Berdasarkan data SDKI tahun 2007 didapatkan fenomena permasalahan pada masa menyusui banyak terjadi pada usia diatas 25 tahun sepertiga wanita di Dunia (38\%) didapati tidak menyusui bayinya karena terjadi pembengkakan payudara. Angka cakupan ASI eksklusif mencapai $32,3 \%$ ibu yang memberikan ASI ekslusif pada anaknya. Dalam suatu penelitian nyeri pada ibu terjadi dalam waktu tertentu selama 6 minggu. Duktus tersumbat dapat menimbulkan nyeri pada payudara, nyeri biasanya timbul hanya pada satu payudara dan hanya sedikit rasa hangat dirasakan atau tidak ada rasa hangat sama sekali (Wheeler, 2004).

Penatalaksanaan kompres dingin dapat mengurangi rasa sakit payudara, untuk mengurangi statis di vena dan pembuluh getah bening lakukan pengurutan payudara yang di mulai dari putting ke arah corpus. 


\section{RUMUSAN MASALAH}

Permasalahan yang disimpulkan sesuai dengan uraian diatas yaitu Bagaimana Gambaran penyebab terjadinya pembengkakan payudara pada ibu menyusui di Polindes Desa Meddelan Kecamatan Lenteng Kabupaten Sumenep Tahun 2017 ? “

\section{TUJUAN PENELITIAN}

Mengetahui penyebab terjadinya pembengkakan payudara pada ibu menyusui di Polindes Desa Meddelan Kecamatan Lenteng Kabupaten Sumenep Tahun 2017.

\section{METODE PENELITIAN}

Jenis penelitian ini merupakan penelitian Deskriptif , sampelnya adalah jumlah semua ibu menyusui di Polindes Desa Meddelen yang berjumlah 25 orang, menggunakan tekhnik total sampling dan penyajian datanya menggunakan distribusi frekuensi dan tabulasi silang

\section{HASIL PENELITIAN}

\section{A. Data Umum}

1) Karakteristik Responden berdasarkan umur Tabel 1 Distribusi frekuensi responden berdasarkan umur di Desa Meddelan Kecamatan Lenteng

\begin{tabular}{cccc}
\hline \multirow{2}{*}{ No } & \multirow{2}{*}{ Umur } & \multicolumn{2}{c}{ Responden } \\
\cline { 3 - 4 } & & $\mathbf{F}$ & $\%$ \\
\hline 1 & $17-25$ tahun & 7 & 28 \\
2 & $26-35$ tahun & 16 & 64 \\
3 & $36-45$ tahun & 2 & 8 \\
\hline & Jumlah & 25 & 100
\end{tabular}

Berdasarkan Tabel 1 dapat dilihat bahwa dari 25 ibu menyusui di Desa Meddelan Kecamatan Lenteng Kabupaten Sumenep sebagian besar responden umur 26-35 tahun sebanyak 16 (64\%) ibu menyusui mengalami pembengkakan payudara yang berat.

2) Karakteristik Responden berdasarkan pendidikan

Tabel 2 Distribusi frekuensi responden berdasarkan pendidikan di Desa Meddelan Kecamatan Lenteng Kabupaten Sumenep

\begin{tabular}{cccc}
\hline \multirow{2}{*}{ No } & \multirow{2}{*}{ Pendidikan } & \multicolumn{2}{c}{ Responden } \\
\cline { 3 - 4 } & & $\mathbf{F}$ & $\mathbf{( \% )}$ \\
\hline 1 & SD & 5 & $32 \%$ \\
2 & SMP & 10 & $40 \%$ \\
3 & SMA & 2 & $8 \%$ \\
4 & Perguruan tinggi & 25 & $100 \%$ \\
\hline
\end{tabular}

Berdasarkan Tabel 2 dapat dilihat bahwa dari 25 ibu menyusui di Desa Meddelan Kecamatan Lenteng Kabupaten Sumenep hampir setengahnya responden yang berpendidikan SMA sebanyak 10 (40\%) ibu menyusui.

3) krakteristik responden berdasarkan pekerjaan

Tabel 3 Distribusi frekuensi responden berdasarkan Pekejaan di Desa Meddelan Kecamatan Lenteng Kabupaten Sumenep

\begin{tabular}{cccc}
\hline No & Pekerjaan & $\mathbf{F}$ & $\%$ \\
\hline $\mathbf{1}$ & IRT & 16 & 64 \\
2 & Petani & 3 & 12 \\
3 & Swasta & 5 & 20 \\
4 & PNS & 1 & 4 \\
\hline & Jumlah & 25 & 100 \\
\hline
\end{tabular}

Berdasarkan Tabel 3 dapat dilihat bahwa dari 25 ibu menyusui di Desa Meddelan Kecamatan Lenteng Kabupaten Sumenep hampir sebagian besar responden yang bekerja sebagai IRT sebanyak 16 (64\%) ibu menyusui.

\section{B. Data Khusus}

1) Stres pada ibu menyusui

Tabel 4 Distribusi frekuensi berdasarkan tingkat stress pada lbu Menyusui di Desa Meddelan Kecamatan Lenteng Kabupaten Sumenep

\begin{tabular}{cccc}
\hline No & Stress & F & $\%$ \\
\hline 1 & Normal & 3 & 12 \\
2 & Ringan & 7 & 28 \\
3 & Sedang & 5 & 20 \\
4 & Parah & 8 & 32 \\
5 & Sangat parah & 2 & 8 \\
\hline & Jumlah & 25 & 100 \\
\hline
\end{tabular}

Berdasarkan Tabel 4 di atas dapat diketahui dari 25 ibu menyusui di Desa Meddelan Kecamatan Lenteng Kabupaten Sumenep hampir setengahnya responden memiliki tingkat stress yang parah yaitu sebanyak $8(32 \%)$ ibu menyusui.

\section{2) Tekhnik menyusui}

Tabel 5 Distribusi frekuensi berdasarkan tekhnik menyusui pada ibu menyusui di Desa Meddelan Kecamatan Lenteng Kabupaten Sumenep

\begin{tabular}{cccc}
\hline No & Teknik Menyusui & F & $\%$ \\
\hline 1 & Baik & 5 & 20 \\
2 & Cukup & 8 & 32 \\
3 & Kurang & 12 & 48 \\
\hline & Jumlah & 25 & 100 \\
\hline
\end{tabular}

Berdasarkan Tabel 5 dapat dilihat bahwa dari 25 ibu menyusui di Desa Meddelan Kecamatan Lenteng Kabupaten Sumenep 
hampir setengahnya responden menerapkan tekhnik menyusui yang kurang sebanyak 12 (48\%) ibu menyusui

\section{Perawatan payudara}

Tabel 6 Distribusi frekuensi berdasarkan perawatan payudara pada ibu menyusui di Desa Meddelan Kecamatan Lenteng Kabupaten Sumenep

\begin{tabular}{cccc}
\hline No & Perawatan Payudara & F & $\%$ \\
\hline 1 & Baik & 2 & 8 \\
2 & Cukup & 4 & 16 \\
3 & Kurang & 19 & 76 \\
\hline & Jumlah & 25 & 100
\end{tabular}

Berdasarkan tabel 6 diketahui bahwa dari 25 responden di Desa Meddelan Kecamatan Lenteng Kabupaten Sumenep hampir seluruhnnya responden melakukan perawatan payudara yang kurang yaitu sebanyak 19 (76\%)ibu menyusui.

1. Pembengkakan payudara tabel 7 dsitribusi frekuensi responden di Desa Meddelan Kecamatan Lenteng Kabupaten Sumenep

\begin{tabular}{cccc}
\hline \multirow{2}{*}{ No } & $\begin{array}{c}\text { Pembengkakan } \\
\text { payudara }\end{array}$ & \multicolumn{2}{c}{ Responden } \\
\cline { 3 - 4 } & Ringan & F & $\%$ \\
\hline 1 & Sedang & 7 & 40 \\
2 & Berat & 8 & 32 \\
3 & Jumlah & 25 & 100 \\
\hline \multicolumn{2}{c}{ Berdasarkan tabel } & 7 & diketahui
\end{tabular}
bahwa dari 25 responden di Desa Meddelan Kecamatan Lenteng Kabupaten Sumenep hampir setengahnya responden mengalami pembengkakan payudara yang ringan yaitu sebanyak $10(40 \%)$ ibu menyusui.

2. Tabulasi silang antara stress pada ibu menyusui dengan pembengkakan payudara pada ibu menyusui di Desa Meddelan Kecamatan Lenteng.

Tabel 8 Tabulasi silang antara stress pada ibu menyusui dengan pembengkakan payudara pada ibu menyusui di Desa Meddelan Kecamatan Lenteng.

\begin{tabular}{|c|c|c|c|c|c|c|c|c|c|}
\hline \multirow{2}{*}{ No } & \multirow{2}{*}{ Stress } & \multicolumn{6}{|c|}{ Pembengkakan payudara } & \multicolumn{3}{|c|}{ Total } \\
\cline { 3 - 10 } & & Ringan & $\%$ & Sedang & $\%$ & Berat & $\%$ & Jumlah & $\%$ \\
\hline 1 & Normal & 1 & 16.7 & 2 & 33.3 & 0 & 0 & 3 & 100 \\
\hline 2 & Ringan & 2 & 50 & 1 & 25 & 4 & 57.1 & 7 & 100 \\
\hline 3 & Sedang & 3 & 60 & 2 & 40 & 0 & 0 & 5 & 100 \\
\hline 4 & Parah & 2 & 25 & 2 & 25 & 4 & 50 & 8 & 100 \\
\hline 5 & Sangat parah & 2 & 100 & 0 & 0 & 0 & 0 & 2 & 100 \\
\hline \multicolumn{2}{|l}{ Jumlah } & 10 & 40 & 7 & 28 & 8 & 32 & 25 & 100 \\
\hline
\end{tabular}

Berdasarkan tabel diatas ibu menyusui yang seluruhnya (100\%) mengalami pembengkakan mengalami tingkat stress yang sangat parah payudara yang ringan.

3. Tabulasi silang antara tekhnik menyusui dengan pembengkakan payudara pada ibu menyusui di Desa Meddelan Kecamatan Lenteng.

Tabel 9 Tabulasi silang antara tekhnik menyusui dengan pembengkakan payudara pada ibu menyusui di Desa Meddelan Kecamatan Lenteng.

\begin{tabular}{|c|c|c|c|c|c|c|c|c|c|}
\hline \multirow{2}{*}{ No } & \multirow{2}{*}{$\begin{array}{l}\text { Tekhnik } \\
\text { menyusui }\end{array}$} & \multicolumn{6}{|c|}{ Pembengkakan payudara } & \multicolumn{2}{|c|}{ Total } \\
\hline & & Ringan & $\%$ & Sedang & $\%$ & Berat & $\%$ & Jumlah & $\%$ \\
\hline 1 & Kurang & 6 & 50 & 2 & 16.7 & 4 & 33.3 & 12 & 100 \\
\hline 2 & Cukup & 4 & 50 & 4 & 50 & 0 & 0 & 8 & 100 \\
\hline 3 & Baik & 0 & 0 & 1 & 20 & 4 & 80 & 5 & 100 \\
\hline & Jumlah & 10 & 40 & 7 & 28 & 8 & 32 & 25 & $100 \%$ \\
\hline
\end{tabular}

Berdasarkan tabel diatas ibu menyusui baik hampir seluruhnya (80\%) mengalami yang melakukan tekhnik menyusui yang pembengkakan payudara yang berat

4. Tabulasi silang antara perawatan payudara dengan pembengkakan payudara pada ibu menyusui di Desa Meddelan Kecamatan Lenteng.

Tabel 10 Tabulasi silang antara perawatan payuadara dengan pembengkakan payudara pada ibu menyusui di Desa Meddelan Kecamatan Lenteng. 


\begin{tabular}{|c|c|c|c|c|c|c|c|c|c|}
\hline \multirow{2}{*}{ No } & \multirow{2}{*}{$\begin{array}{c}\text { Perawatan } \\
\text { Payudara }\end{array}$} & \multicolumn{6}{|c|}{ Pembengkakan payudara } & \multicolumn{2}{|c|}{ Total } \\
\hline & & Ringan & $\%$ & Sedang & $\%$ & Berat & $\%$ & Jumlah & $\%$ \\
\hline 1 & Kurang & 10 & 52.6 & 4 & 21.1 & 5 & 26.3 & 19 & 100 \\
\hline 2 & Cukup & 0 & 0 & 2 & 50 & 2 & 50 & 4 & 100 \\
\hline 3 & Baik & 0 & 0 & 1 & 50 & 1 & 50 & 2 & 100 \\
\hline & Jumlah & 10 & 40 & 7 & 28 & 8 & 32 & 25 & 100 \\
\hline
\end{tabular}

Berdasarkan tabel diatas ibu menyusui yang melakukan perawatan payudara yang kurang

sebagian besar (52.6\%) mengalami
pembengkakan payudara yang ringan.

\section{PEMBAHASAN}

\section{Stress pada ibu menyusui}

Hasil penelitian tentang stress pada ibu menyusui pada tabel 4 Distribusi frekuensi berdasarkan tingkat stress pada ibu menyusui. Hampir setengahnya responden memiliki tingkat stress yang parah yaitu sebanyak $8(32 \%)$ ibu menyusui. Ciri stres pada ibu menyusui biasanya timbul gejala seperti gangguan tidur, kelelahan fisik dan mental serta jantung berdebar sangat keras (Hawari, 2001). Menurut (Saleha, 2009) Stress akan mempengaruhi proses pikir, jika proses pikir terganggu akan mempegaruhi perilaku. Hal ini dapat terjadi pada ibu menyusui, ibu yang stress akan mempengaruhi tehnik dan cara menyusuinya karena tidak konsentrasi.

Penelitian yang dilakukan oleh Shinta Ratna Angraini mahasiswa D IV Kebidanan Fakultas Kedokteran Universitas Sebelas Maret Surakarta Tahun 2011 yang berjudul perbedaan tingkat stress dalam proses menyusui di RSUD kota Surakarta, mendapatkan hasil terdapat perbedaan rerata yang signifikan antara skor tingkat stress dalam proses menyusui.

Menyimpulkan dari teori dan beberapa penelitan yang ada, maka dapat diketahui stress memanglah faktor yang kuat mempengaruhi lancarnya pemberian ASI pada bayi, karena di tempat penelitian banyak ibu yang stresspada masa menyusui, sehingga menyebabkan pengeluaran ASInya menjadi tidak lancar dan bisa menyebabkan pembengkakan payudara. Berdasarkan data yang di dapatkan, stress akan datang pada ibu yang masih memiliki pengalaman pertama melahirkan dalam kehidupannya, karena kurangnya informasi yang diterima, cara pemahaman informasi yang kurang, serta rasa khawatir ibu yang terlalu berlebihan pada keadaan yang sedang terjadi. Sehingga semakin tinggi tingkat stress ibu akan mempengaruhi kerja hormon yang akan memproduksi ASI dan akhirnya menyebabkan jumlah ASI yang keluar menjadi sedikit atau bahkan terhambat dan tidak diproduksi sama sekali dan bisa menyebabkan pembengkakan payudara.

Rasa khawatir, stress atau masalah psikologi yang dihadapi ibu khususnya pada masa menyusui perlu dicegah sejak dini, tentunya hal tersebut membutuhkan peran dari pihak yang terdekat terlebih dahulu, seperti keluarga, suami, teman, dan lingkungan sekitar. Dengan pemberian informasi tentang menyusui, curahan kasih sayang, meringankan pekerjaan ibu, dan membantu merawat bayi, dengan begitu ibu atau calon ibu akan lebih percaya diri menghadapi keadaan yang akan terjadi. Oleh karena itu peran tenaga kesehatan penting untuk melakukan praktek pemberian inisiasi menyusui dini (IMD), deteksi dini tingkat stress ibu dengan kuesioner DASS, pemberikan Informasi cara merawat bayi, perawatan payudara sebelum dan sesudah melahirkan,sertacara menyusui yang benar, agar ibu dapat mengetahui sejak dini berbagai gejala dan penangan awal ketika ibu mengalami hal yang tidak nyaman pada dirinya.

\section{Tekhnik menyusui}

Tabel 5 Distribusi frekuensi berdasarkan tekhnik menyusui pada ibu dapat dilihat bahwa hampir setengahnya responden menerapkan tekhnik menyusui yang kurang sebanyak (48\%) ibu menyusui. Tabel 9 tentang tabulasi silang antara tehnik menyusui dengan pembengkakan payudara menyebutkan bahwa ibu menyusui yang melakukan tekhnik menyusui yang kurang, setengahnya (50\%) mengalami pembengkakan payudara yang ringan. Secara deskriptif diduga tidak ada hubungan antara tehnik menyusui dengan pembengkakan payudara.

Dari data diatas dapat disimpulkan secara deskriptif tekhnik menyusui pada ibu dapat dilihat bahwa hampir setengahnya responden menerapkan tekhnik menyusui yang kurang, dan semakin parah tingkat stress ibu menyusui semakin kurang tehnik menyusui, 
namun tampak tidak ada hubungan antara tekhnik menyusui dengan pembengkakan payudara.

Tekhnik menyusui yang kurang pada ibu menyusui secara deskriptif tampak tidak ada hubungannya dengan pembengkakan payudara pada ibu menyusui karena tetap memberikan ASI kepada bayinya, sehingga ASI tetap keluar dan pembengkakan payudara tidak akan terjadi.

Ibu menyusui seharusnya tahu cara dan tekhnik menyusui yang benar yaitu dengan memperhatikan akibat tidak menyusui dengan benar yaitu puting susu lecet, ASI tidak keluar secara optimal sehingga mempengaruhi produksi ASI, bayi enggan menyusu dan bayi menjadi kembung (Saryono, 2008;h.30). Prinsip menyusui yang benar yaitu memberi ASI dalam suasana yang santai bagi ibu dan bayi, buat kondisi ibu senyaman mungkin. Selama beberapa minggu pertama, bayi perlu diberi ASI setiap 2,5 - 3 jam sekali, menjelang akhir minggu ke enam, sebagian besar kebutuhan bayi akan ASI setiap 4 jam sekali, jadwal ini baik sampai berumur antara 10-12 bulan. Pada usia ini sebagian besar bayi tidur sepanjang malam sehingga tidak perlu lagi memberi makan di malam hari (Saryono, 2008).

$\mathrm{Hal}$ ini berbeda dengan yang ditemukan dilapangan saat penelitian karena banyak ibu menyusui dilapangan tidak melakukan urutan tindakan menyusui yang benar yaitu seperti tidak memperhatikan perlekatan dan posisi yang benar saat menyusui. Untuk mengatasi masalah diatas, maka ibu menyusui yang malas memperhatikan tekhnik dan caramenyusui yang benar sebaiknya diberikan pelatihan tehnik menyusui yg benar dianjurkan untuk menerapkan urutan tindakan menyusui yang benar.Selain itu, bagi ibu menyusui yang menganggap bahwa langkah-langkah dalam tekhnik menyusui terlalu rumit maka sebaiknya mengajarkan pada ibu menyusui tiap-tiap langkah dalam melakukan tekhnik menyusui yang benar sampai ibu menyusui benar-benar memahami akibat jika bayi tidak disusui dengan benar.

\section{Perawatan payudara pada ibu menyusui}

Tabel 6 Distribusi frekuensi berdasarkan perawatan payudara pada ibu hampir seluruhnnya responden melakukan perawatan payudara yangkurangyaitu sebanyak 19 (76\%) ibu menyusui.

Berdasarkan tabel tabel 10 Tabulasi silang antara ibu menyusui yang melakukan perawatan payudara yang kurang sebagian besar (52.6\%) mengalami pembengkakan payudara yang ringan. Secara deskriptif diduga tidak ada hubungan antara perawatan payudara dengan pembengkakan payudara.

Dari data diatas dapat disimpulkan secara deskriptif perawatan payudara pada ibudapat dilihat bahwa hampir seluruhnnya responden melakukan perawatan payudara yangkurang, dan semakin kurang perawatan payudara ibu menyusui semakin ringan tingkat pembengkakan payudara, namun diduga tidak ada hubungan antara perawatan payudara dengan pembengkakan payudara.

Perawatan payudara pada ibu menyusui tidak ada hubungannya dengan pembengkakan payudara pada ibu menyusui karena tetap memberikan ASI kepada bayinya, sehingga ASI tetap keluar dan pembengkakan payudara tidak akan terjadi.

Perawatan payudara yang teratur bisa memelihara kebersihan puting susu dan memperlancar produksi ASI maka lbu menyusui sebaiknya melakukannya. Untuk mengatasi masalah diatas, dapat dilakukan penyuluhan tentang pentingnya perawatan payudara saat kunjungan, ibu menyusui dianjurkan penerapan proses perawatan payudara. mengajarkan langkah-langkah melakukan perawatan payudara sampai ibu menyusui mengerti, memahami dan mampu melakukan perawatan payudara dengan mandiri.

\section{Pembengkakan payudara pada ibu menyusui}

Tabel 7 Distribusi frekuensi berdasarkan pembengkakan payudara pada ibu menyusui hampir setengahnya responden mengalami pembengkakan payudara yang ringan yaitu sebanyak (40\%) ibu menyusui.

Pekerjaan ibu menyusui yang sebagian besar IRT / tidak bekerja jadi banyak waktu luang untuk menyusui walaupun hampir setengahnya menerapkan tekhnik menyusuinya salah dan hampir setengahnya yang mengalami stress tetapi tetap memberikan ASI. Hampir setengahnya Pendidikan ibu menyusui SMA maka mempunyai kesadaran untuk memberikan ASI. Jadi dapat disimpulkan secara deskriptif pekerjaan dan pendidikan mungkin berpengaruh terhadap pembengkakan payudara.

Menyusui yang tidak berkelanjutan menyebabkan pembengkakan pada payudara sehingga sisa ASI menumpuk di area duktus yang bisa terjadi pada hari ke tiga setelah melahirkan. Penggunaan bra yang ketat dan 
puting susu yang kotor dapat mengakibatkan sumbatan pada duktus laktiferus. Tersumbatnya duktus laktiferus dapat terjadi pada satu atau lebih saluran yang diakibatkan oleh pemakaian $\mathrm{BH}$ terlalu ketat, tekanan jarijari ibu saat menyusui, sumbatan ASI yang terkumpul karena tidak segera dikeluarkan yang akibatnya payudara menjadi bengkak (Bahiyatun, 2009).

Untuk mengatasi masalah diatas, maka ibu menyusui yang tidak mengetahui dan ibu yang mengetahui namun tidak memeriksakan payudara sebaiknya diberikan penyuluhan mengenai cara untuk mencegah terjadinya payudara bengkak antara yaitu dengan cara dengan posisi dan perlekatan yang benar saat menyusui bayi yang baru lahir, tanpa jadwal menyusui, mengeluarkan ASI dengan tangan/pompa jika produksi lebih dari kebutuhan bayi, tidak memberi minuman lain pada bayi, melakukan perawatan payudara setelah persalinan (masase dan gunakan $\mathrm{BH}$ untuk menopang payudara).

\section{Kesimpulan}

1. Hampir setengahnya ibu menyusui mengalami tingkat stress yang parah.

2. Hampir setengahnya ibu menyusui melakukan tekhnik menyusui yang kurang

3. Hampir seluruhnnya responden melakukan perawatan payudara yang kurang

4. Hampir setengahnya responden mengalami pembengkakan payudara yang ringan

\section{Saran}

1. Bagi Masyarakat

a. Meningkatkan pengetahuannya dengan membaca dan memperoleh informasi tentang tingkat stress, tehnik menyusui yang benar dan perawatan payudara.

b. Meningkatkan tekhnik meyusui yang benar agar ASI keluar lancar dan tidak terjadi pembengkakan payudara.

2. Bagi Bidan

a. Bidan memberikan pendidikan kesehatan pada ibu menyusui mengenai faktor faktor yang menyebabkan pembengkakan payudara. b. Berikan konseling pada ibu menyusui untuk menjaga personal hygiene atau kebersihan payudara agar terhindar dari pembengkakan payudara.

3. Bagi Penelitian Selanjutnya

Meneliti faktor lainnya yang mengakibatkan pembengkakan payudara pada ibu menyusui, misalnya nutrisi ibu menyusui dan pengaruh budaya.

\section{DAFTAR PUSTAKA}

Aini. (2009). Pembengkakan Payudara Ibu Post Seksio Sesarie Pada Masa Menyusui di Rumah Sakit Umum Daerah Ade Mohammas Djoen Sintang . Breast Swelling And Breastfeeding, 96.

Ai yeyeh, dkk. Asuhan Kebidanan Patologi. Jakarta: Trans Info

Ambarwati, dkk. 2010. Asuhan Kebidanan Nifas. Yogyakarta : Nuha Medika.

Anggraini. 2010. Asuhan Kebidanan Masa Nifas. Yogyakarta: Pustaka Rihama

Asfuah, P. d. (2009). pemberian kompres panas terhadap penurunan nyeri payudara pada asuhan keperawatan Ny.Y dengan post partum spontan diruang mawar 1 rumah sakit Dr.Moewardi Surakarta. surakarta: prodi studi DIII Keperawatan Sekolah Tinggi Ilmu Kesehatan Kusuma Husada

Astutik, Reni Yuli. 2014. Payudara dan Laktasi. Jakarta : Salemba medika

Bahiyatun. (2009). Pemberian Kompres Panas Terhadap Penurunan Nyeri Payudara Pada Asuhan Keperawatan Ny.Y dengan Post Partum Spontan di Ruang Mawar 1 Rumah Sakit Dr.Moewardi Surakarta. Surakarta: Prodi Studi DIII Keperawatan Sekolah Tinggi IImu Kesehatan Kusuma Husada.

Bobak. (2004). Tingkat Pengetahuan Ibu nifas Tentang bendungan $A S I$ di RB AN NUUR Sumber Program Studi. Surakartta: Diploma III Kebidanan Sekolah Tinggi IImu Kesehatan Kusuma Husada 